\title{
Characterization of Convective Transfer of Heat by Air Impingement using Single Swirling Jet with Insertion of Twisted Tapes by Computational Fluid Dynamics
}

\author{
Rakesh Kumar, Yogesh Kumar
}

\begin{abstract}
This study showed the analysis of heat transfer by computational fluid dynamics (CFD) from a heated target surface by the use of jet of single swirl and impingement by air at various Reynolds numbers. The half-length downstream with insertion of twisted tape is applied in a nozzle body to get the swirl. The distance between twist ratio and nozzle to plate of twisted tape is found to be same as $y=2.93$ and $21 \mathrm{~mm}(\mathrm{H} / \mathrm{D}=1)$. The characteristics of transfer of heat on heated surface are determined with varied Reynolds numbers like 12000, 17000, 22000 and 27000.
\end{abstract}

Keywords: Computational Fluid Dynamics, Heat transfer, Swirling jet, Reynolds number.

\section{I.INTRODUCTION}

The impingement by jet is latest important technique for enhancement of heat transfer. Due to more transfer of heat and other benefits these methods is mainly applied in large applications of engineering and other fields. For example chemical vapour deposition, turbine blades cooling, to dry food products, textiles, films and papers,cooling of electronically used equipment, cooling the outside wall of combustion chamber etc. Various literatures was found on various forms like single and multiple jets with co-relations produced for characteristics of mass and heat transfer connected to this area. The main problem based on impingement by jet is the high non uniformity of the local heat flux (Remie, 2007) [1]. To reduce the limitations of radial non-uniformity different tests were taken by various forms. This problem is solved by introduction of jet in swirl form. Amini Younes (2015)[2] observed the similar radial distribution of transfer of heat is produced by a swirling jet in comparison of non-swirling jet. Different studies were conducted by experimental, empirical and numerical methods. Much literature (Hady, M.F (1997) [3] and (Zuckerman, Neil (2006) [4] was found related to this. Many experiments are needed to get the knowledge of characteristics of transfer of heat by the plate impingement.

Revised Manuscript Received on February 05, 2020.

* Correspondence Author

Rakesh Kumar, Department of Mechanical Engineering, Ludhiana Group of Colleges, Chokimann, Ludhiana, Punjab, India

Yogesh Kumar, Department of Electronics Engineering, CT Group of Institutions Jalandhar, Punjab, India

(C) The Authors. Published by Blue Eyes Intelligence Engineering and Sciences Publication (BEIESP). This is an open access article under the CC BY-NC-ND license (http://creativecommons.org/licenses/by-nc-nd/4.0/)
Ianiro, Andrea (2012) [5] performed experiments to observe and compare the results of impinging of jets by swirling and multi-channel by the impinging jet of conventional method (CIJ), keeping the radius is same at the similar applications. Qing, Zheng (1997) [6] also studied to know the flow of air in swirl form in a cylindrical hole by the technique of the smoke wires. The picture of the discharge area was not accurate and also not showed the complete discharge field as comparison to the Bhatt, Shibani (2019) [7]. Various methods are implemented by various overall coefficient of heat transfer. The thermo chromic liquid crystal is one out of the various methods. That technique is implemented by Yeranee, K (2017) [8]. Different experiments were conducted at same distance between nozzle and plate at $\mathrm{L}=4 \mathrm{D}$ to study the characteristics of flow and transfer of heat by a jet of swirl impingement. Benmouhoub, Dahbia (2013) [9] adopted a swirl generator prepared by a plug of cylindrical shape to supply swirl to jets of single and multiple with four narrow channels. It has been found that increase of Nusselt number and betterment in radial uniformity of transfer of heat was found by jet of swirl impingement as compared to impingement of jets by multichannel and conventional impingement of jet.

\section{NUMERICAL SETUP}

To determine the 3dimensional results of transfer of heat by method of convection on the plate impingement the FLUENT-6.3.26 commercial computational fluid dynamics software was used which is attached with impingement of jets in swirl form with various Reynolds numbers. The computational domain contains the whole assembly of pipe and plate as represent in figure1. The designed was made by flow of air with a diameter of tube (D) $21 \mathrm{~mm}$ including twisted tape as in swirl shape (HLDI) and $300 \mathrm{~mm}$ length (L) impinge upon a flat plate which is heated at constant $3000 \mathrm{~W} / \mathrm{m}^{2}$ heat flux. The testing of geometry was taken at various Reynolds numbers as 12000, 22000, 17000 and 27000. The design selected for experiment is represented in figure2, where HLDI represents configuration of half-length downstream insert. 
Characterization of Convective Transfer of Heat by Air Impingement using Single Swirling Jet with Insertion of Twisted Tapes by Computational Fluid Dynamics

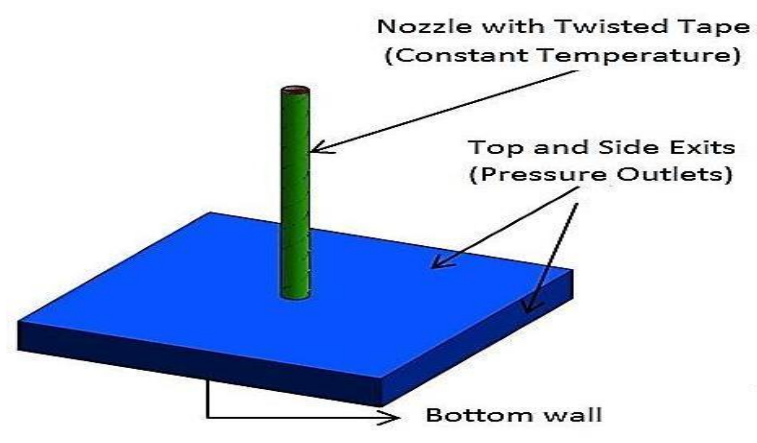

Figure1 Assembly of pipe and plate

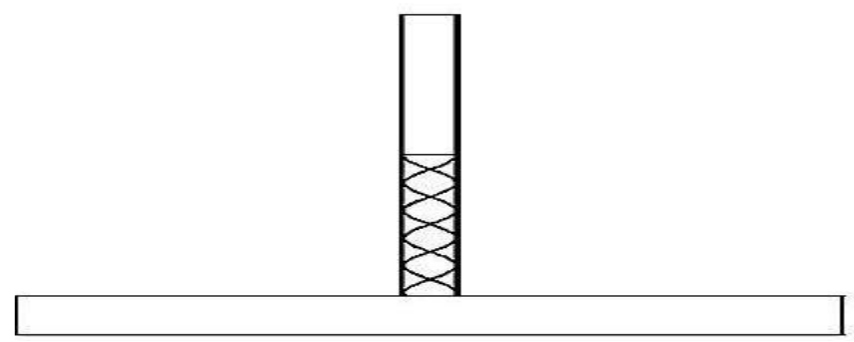

Figure 2 The configuration chosen for study

\section{NUMERICAL SIMULATION}

Figure 3 represents sketch of computational domain for simulation by commercial computational fluid dynamics software FLUENT 6.3.26 and Table 1 shows conditions at the boundary used for this simulation at different parts of the computational domain.

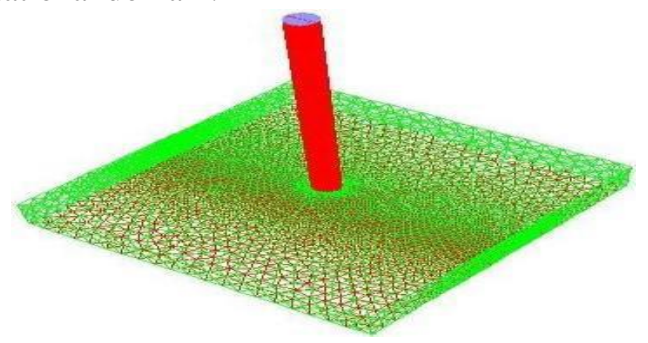

Figure 3 Computational domain used for simulation To resolve the fluid flow the numbers of cells used for this domain are near about12, 50,808 which are sufficient. To obtain prediction of heat transfer the fields of discharge and turbulence have to be solved in accurate way. To represent the all terms of heat transfer scheme of second order is used. This scheme is applied for the pressure; turbulence kinetic energy, momentum, specific dissipation rat etc. The standard SIMPLE algorithm is applied for the coupling of pressure and velocity. The way of simulation is used at condition of steady state convergence control is fixed at maximum 1000 trials, criteria of convergence is given as 10E-05 residuals and that can be varied if criteria of convergence is not obtained. The 3D equations of NavierStokes and energy are solved by using computational fluid dynamics software (FLUENT 6.3.26) which is attached with momentum and continuity equations to simulate fields of heat and flow of turbulence. There are various types of models available for turbulence but the shear stress transport is the best model for this configuration of flow and is also selected because of its simplicity, wide acceptability and economy.
Table 1.Boundary condition

\begin{tabular}{|c|c|c|}
\hline $\begin{array}{c}\text { Geometrical Identity/ } \\
\text { Physical Location }\end{array}$ & Type of Boundary & Color \\
\hline Outlet / Top Surface Opening & Outlet Pressure & Green \\
\hline $\begin{array}{c}\text { Impingement Plate / Bottom } \\
\text { Surface }\end{array}$ & Wall & Red \\
\hline Outlet/ Side Opening & Outlet Pressure & Green \\
\hline Twisted Tape / Centre & Wall & Red \\
\hline Nozzle Inlet / Inlet & Inlet Velocity & Blue \\
\hline Nozzle Wall & Wall & Red \\
\hline
\end{tabular}

\section{GOVERNING EQUATIONS FOR TRANSFER OF HEAT}

The Newton's law of cooling was used to transfer of heat from solid surface to movement of fluid can be represented by:

$$
\mathrm{q}=\mathrm{h}\left(\mathrm{T}_{\square} \square \mathrm{T}_{\mathrm{S}}\right)(1)
$$

in which $\mathrm{q}$ is the flux of heat from the solid to the moving fluid, $h$ is convective coefficient of transfer of heat, $T_{\infty}$ is the reference temperature and $T_{S}{ }^{e e}$ is the for the temperature of the system. The temperature difference is like a tension for convection.The coefficient of transfer of heat (h) is nondimensionalized using the length scale (D) and thermal conductivity $\left(\mathrm{K}_{\mathrm{t}}\right)$ which represents the design. This gives a number which is dimensional less called Nusselt ${ }^{e c}$ s number (Nu):

$$
\begin{gathered}
\mathrm{N}_{\mathrm{u}}={ }^{\mathrm{hD}} \\
{ }^{(2)} \mathrm{K}_{\mathrm{t}}
\end{gathered}
$$

The Nusselte's number $(\mathrm{Nu})$ is a major feature of the design, the velocity of flow and the fluid's physical properties. Normally various relations are obtained between the Reynolds number (Re), Nusseltes number $(\mathrm{Nu})$, Prandtl number (Pr) and a dimensional less parameter of geometry.

\section{GRID DEPENDENCY TEST}

This test influences the simulation results directly as represented in table 2. The test of dependency of Grid was conducted to compare the deviations in largest values of Nusselt"s number. These calculations were conducted at Reynolds number 12000 by without insertion of twisted tape and at a distance of jet to plate $2(\mathrm{H} / \mathrm{D}=2)$. These calculations are shown in the table 2 . It was found from this table that with 12, 50,808 cells provide accurate calculation at less computation time to resolve the fluid flow the amount of cells used in this domain are near about 12, 50,808 these are adequate.

Table 2. Results of dependency of Grid

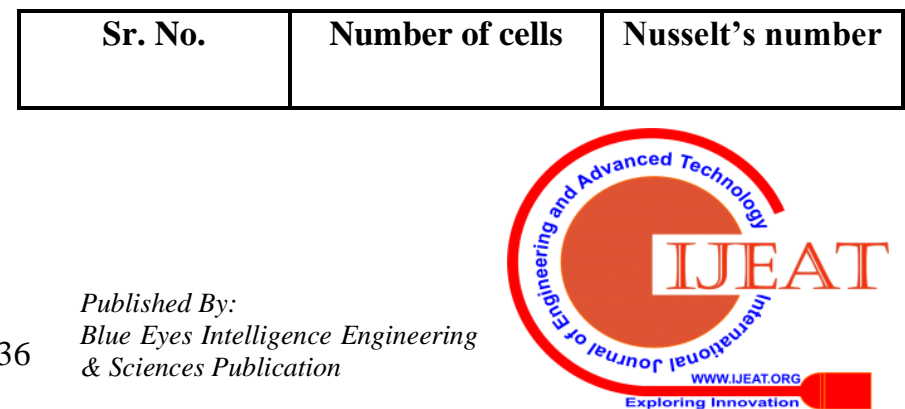




\begin{tabular}{|c|c|c|}
1 & $08,21,751$ & 89.4 \\
\hline 2 & $09,11,627$ & 69.5 \\
\hline 3 & $9,13,630$ & 101.7 \\
\hline 4 & $11,27,328$ & 124.7 \\
\hline 5 & $12,50,808$ & 133.6 \\
\hline 6 & $13,39,937$ & 135.5 \\
\hline 7 & $14,34,630$ & 133.4 \\
\hline 8 & $15,15,536$ & 131.3 \\
\hline
\end{tabular}

and at this value of $\mathrm{X} / \mathrm{D}$ Nusseltes number is improved to 207.86 for Reynolds number $=17000,229.17$ for Reynolds number $=22000$ and 247.05 for Reynolds number $=27000$ this is the largest dimension of Nusselt"s number in this form.

\section{Influence on co-efficient of transfer of heat:}

By the study to know the influence of co-efficient of heat transfer with the variation of Reynolds number it was observed that shows that Co-efficient of transfer of heat increase with the increase in Reynolds number. These are shown as below:

\section{SIMULATION OF SWIRLING IMPINGING JET (SIJ) AND ITS RESULTS}

To study the influence of $\mathrm{Re}$ on the characteristics of transfer of heat the simulation of the fluid flow done for various Re at same twist ratio and separation distance.The separation distances (H/D) applied for this design is $H / D=1$ with twist ratio of twisted tape insert $y=2.93$. Re is changed as Re12000, 17000, 22000 and 27000. The influence of Re on Nusseltes number and coefficient of heat transfer is represented in fig. 4 and 5 respectively.

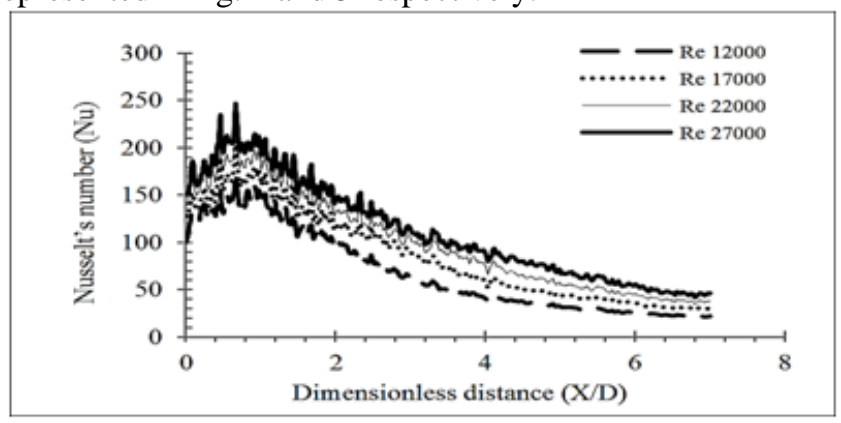

Fig. 4: Variation of Nusselte ${ }^{\text {ee }}$ number w.r.t. X/D for different $\operatorname{Re}$ at $H / D=1$ and for $y=2.93$

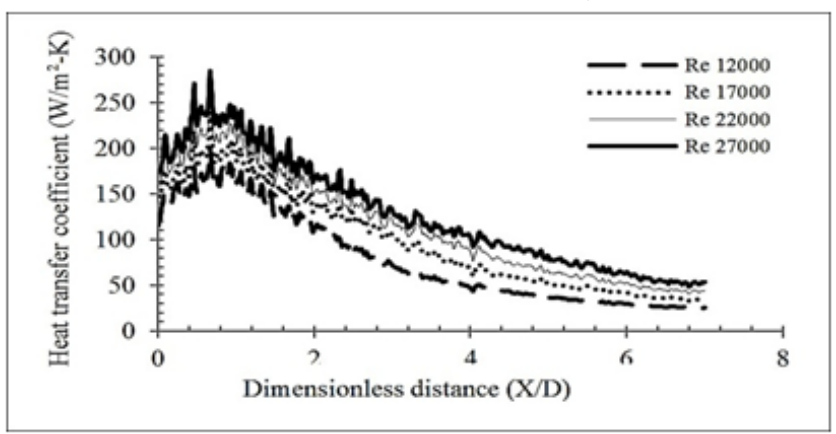

Fig. 5: Variation of coefficient of transfer of heat w.r.t. $\mathrm{X} / \mathrm{D}$ at $\mathrm{H} / \mathrm{D}=1$ and for $\mathrm{y}=2.93$

\section{Influence on Nusselt's number:}

It was shown that the increase in Nusselt's number with the increase in Reynolds number. The values of Nusselt"s number at different Reynolds number for similar configuration and separation distance are given as under: At value of $\mathrm{H} / \mathrm{D}=1$ and for the half-length downstream configuration with the insertion of twisted tape along with twist ratio of 2.93 the Nusseltes number is 100.21 at peak point i.e. $\mathrm{X} / \mathrm{D}=0$ for Reynolds number $=12000$ and dimension will improved to 127.86 for Reynolds number= 17000, 141.51 for Reynolds number $=22000$ and 150.34 for Reynolds number $=27000$. The dimension of Nusselt" $\mathrm{s}$ number is obtained 174.18 at $\mathrm{X} / \mathrm{D}=0.66$ for $\mathrm{Re}=12000$

i. At value of $H / D=1$ and for the form of half-length downstream by the insertion of twisted tape with twist ratio of 2.93 the dimension of co-efficient of transfer of heat at peak point 115.49 at $\mathrm{X} / \mathrm{D}=0$ is and Reynolds number $=$ 12000. The dimension increased to $147.35,163.08,173.25$ with the increase of $\mathrm{Re}=17000,22000$ and $\mathrm{Re}=27000$.

ii. The dimension of coefficient of transfer of heat is obtained to be 200.73 at X/D $=0.66$ and Reynolds number $=12000$ and at this dimension of co-efficient of transfer of heat is improved to 239.53, 264.09, 284.70 for Reynolds number 17000, 22000 and 27000 which is the highest value of co-efficient of transfer of heat. Figure 6 and figure 7 represents the average Nusselte $\mathrm{s}$ number and values of coefficient of heat transfer at varied Reynolds numbers.

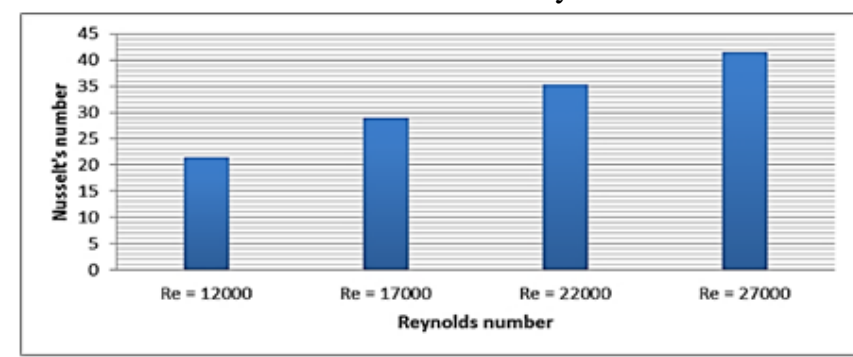

Fig. 5: Variation of average Nusselte's number at varied Reynolds numbers

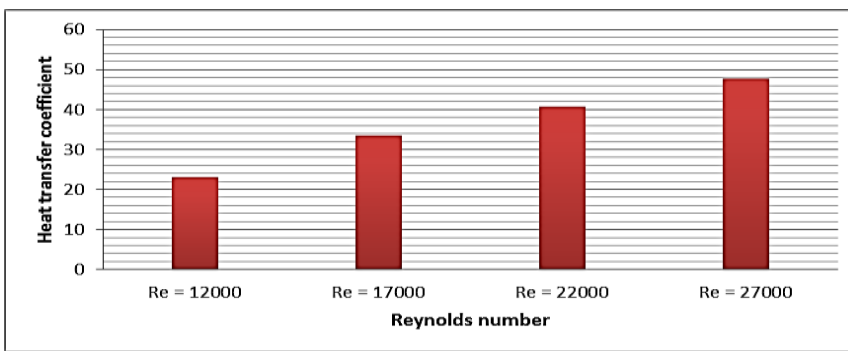

Fig. 6: Variation of average coefficient of heat transfer at varied Reynolds numbers

\section{CONCLUSION}

It was concluded that increase of velocity of jet is a natural way to increase intensity of turbulence of the jet and this was achieved by increase of Reynolds number. As the Reynolds number increased the Nusselt"s number also increased as well as rates of transfer of heat. Due to this, in turbulent flow, the rates of momentum and heat transfer more in comparison to laminar flow. 


\section{Characterization of Convective Transfer of Heat by Air Impingement using Single Swirling Jet with Insertion of Twisted Tapes by Computational Fluid Dynamics}

It was also noticed that this increment due to turbulence achieve largest values as the intensity of turbulence increases for a specific Reynolds number. The Figure7 shows the contours of Nusseltes number for varied range of Reynolds number.

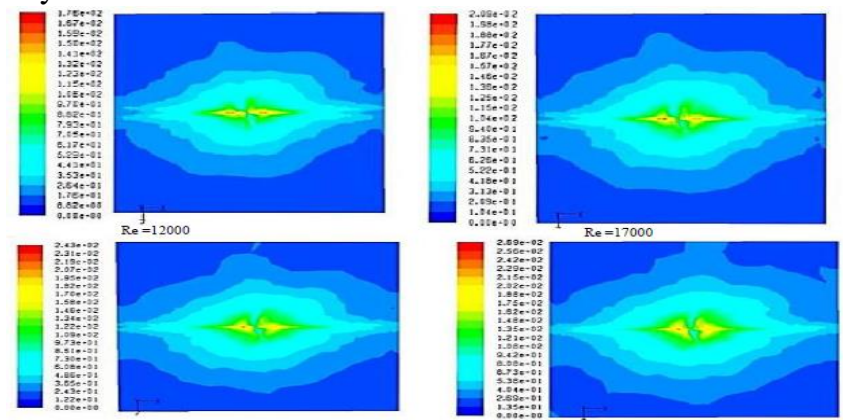

Fig. 7: Map of contours of Nusselt number at varied Reynolds numbers

\section{Nomenclature}

$\mathrm{D}$ : Nozzle diameter in $\mathrm{m}$.

$h$ : coefficient of transfer of heat, w/ $\mathrm{m}^{2} \mathrm{k}$

$k$ : Thermal conductivity in air, $\mathrm{w} / \mathrm{m} \cdot \mathrm{k}$

$\mathrm{Nu}$ : Nusselt number

$q *$ : heat flux in convection

$r$ : Radial distance from the stagnation point, $\mathrm{X} / D$ :

Dimensionless radial distance

Re: Reynolds number based on the outlet diameter, $\mathrm{Re}$ $=\rho u D / \mu$

$u$ : Jet velocity, $\mathrm{m} / \mathrm{s} \rho$ : Air Density, $\mathrm{Kg} / \mathrm{m}^{3}$

$\mu$ : Kinetic viscosity of air, $\mathrm{Kg} / \mathrm{m} \cdot \mathrm{s}$

\section{ACKNOWLEDGMENT}

We would like to thank for this work: Dr.Gurinder Pal Singh Brar, and Dr.M.K.Kushwaha.

\section{REFERENCES}

1. Remie, M.J (2007). "Analysis of the heat transfer of an impinging laminar flame jet," International Journal of Heat and Mass Transfer, pp.2816-2827.

2. Amini Younes., (2015). "Heat transfer of swirling impinging jet ejected from Nozzles with twisted tapes utilizing CFD technique, Vol 6, pp.104-115

3. 3.Hady,M.F (1997), "Forced Convection Heat Transfer on a Flat Plate Embedded in Porous Media for Power-Law Fluids," Transport in Porous Media,Vol.28, pp.125-134.

4. Zuckerman, Neil (2006).“Impingement Heat Transfer: Correlations and Modeling" Journal of Heat Transfer, Vol.5.

5. Ianiro, Andrea (2012), "Heat transfer rate and uniformity in multichannel swirling impinging jets". Applied Thermal Engineering, Vol.49, pp.89-98.

6. Qing,Zheng,(1997) "Local Charactertics of Recovery Factor and Heat Transfer Coefficient with impinging free surface jets of large $\operatorname{Pr}$ Number Liquid" Journal of Engineering Thermo physics

7. Bhatt, Shibani (2019), "Large-scale motions in a plane wall jet", Journal of Fluid Mechanics, Vo.87, pp.239-281.

8. Yeranee, K (2017) "The study of flow and heat transfer characteristics of impinging jet array mounting air-induced duct" IOP Conference Series: Material science and Engineering, Vol.243, conference 1.

9. Benmouhoub, Dahbia (2013). "Turbulence Heat Transfer From a Slot Jet Impinging on a Flat Plate,"Journal of Heat Transfer.
10. Amini Younes., (2015). "Heat transfer of swirling impinging jet ejected from Nozzles with twisted tapes utilizing CFD technique, Vol 6, pp.104-115.

11. Attalla,M (2013). "Stagnation region heat transfer due to a turbulent circular impinging air jets," Journal of Engineering Science, Assiut University, Faculty of Engineering, Vol.41, No 4
Published By:

Retrieval Number: C5246029320/2020@BEIESP
Blue Eyes Intelligence Engineering \& Sciences Publication 